\title{
The Isotope Effect for Electromigration of Sodium Ions in Molten Sodium Nitrate
}

\author{
Nobufusa Saito, Katsumi Hirano, Kohei Okuyama, and Isao OKada * \\ Department of Chemistry, Faculty of Science, University of Tokyo, Hongo, Bunkyo-ku, Tokyo, Japan
}

(Z. Naturforsch. 27 a, 288-293 [1972] ; received 9 July 1971)

The relative difference $(\Delta b / b)$ between the internal electromigration mobilities of ${ }^{22} \mathrm{Na}$ and ${ }^{24} \mathrm{Na}$ in molten $\mathrm{NaNO}_{3}$ has been measured in the range $340-515{ }^{\circ} \mathrm{C}$. The internal mass effect, $\mu_{\text {int }}=(\Delta b / b) /(\Delta m / m)$ is -0.056 at $340^{\circ} \mathrm{C}$ (melting point $308{ }^{\circ} \mathrm{C}$ ), -0.079 at $435{ }^{\circ} \mathrm{C}$ and -0.068 at $515^{\circ} \mathrm{C}$. The errors in $\mu_{\text {int }}$ are \pm 0.002 .

Previous studies of isotope effects of countercurrent electromigration in molten salts have included the alkali nitrates ${ }^{1}$ and thallium nitrate ${ }^{2}$. For $\mathrm{NaNO}_{3}$, SAITO and coworkers ${ }^{3}$ measured the mobility difference between the radioactive isotope ${ }^{22} \mathrm{Na}$ and the stable isotope ${ }^{23} \mathrm{Na}$. The accuracy of that experiment was, however, low, because the specific activity measurement was based on the assumption that the sodium nitrate was pure, while a certain contamination due to thermal decomposition, corrosion of the packing material, etc. could hardly be avoided.

The purpose of the present work is to re-determine the mass effect by using two radioactive isotopes ${ }^{22} \mathrm{Na}$ and ${ }^{24} \mathrm{Na}$ which should enable a higher accuracy, with the object of comparing with the results obtained by zone electromigration ${ }^{4}$ and, at the same time, to confirm the basic assumption that there is no difference whether the mass effect is determined for a tracer isotope $\left({ }^{22} \mathrm{Na}\right)$ and a dominating isotope $\left({ }^{23} \mathrm{Na}\right)$, or for two tracer isotopes $\left({ }^{22} \mathrm{Na}\right.$ and $\left.{ }^{24} \mathrm{Na}\right)$. Another aim of this work is to measure the temperature dependence of the mass effect.

\section{Experimental}

A separation tube of Vycor which had been packed with quartz powder $(100-150$ mesh) was inserted into molten sodium nitrate containing both ${ }^{22} \mathrm{Na}$ and ${ }^{24} \mathrm{Na}$ (Fig. $1 \mathrm{~B}$ ). After the molten salt had risen up to the top of the diaphragm of quartz powder, the separation tube was transferred into another vessel containing molten non-radioactive sodium nitrate (Fig. 1 A), and the electromigration was started. A platinum wire and an aluminum tube were used as the anode and the cathode, respectively. During electromigration, a mixture of nitrogen dioxide and oxygen was bubbled through the cathode tube. After electromigration the separation tube was taken out, allowed to cool, cleaned

* Present address: Department of Physics, Chalmers University of Technology, Göteborg, Sweden, on leave from Tokyo University. thoroughly on the outside wall and cut into sections of $10-15 \mathrm{~mm}$ length.

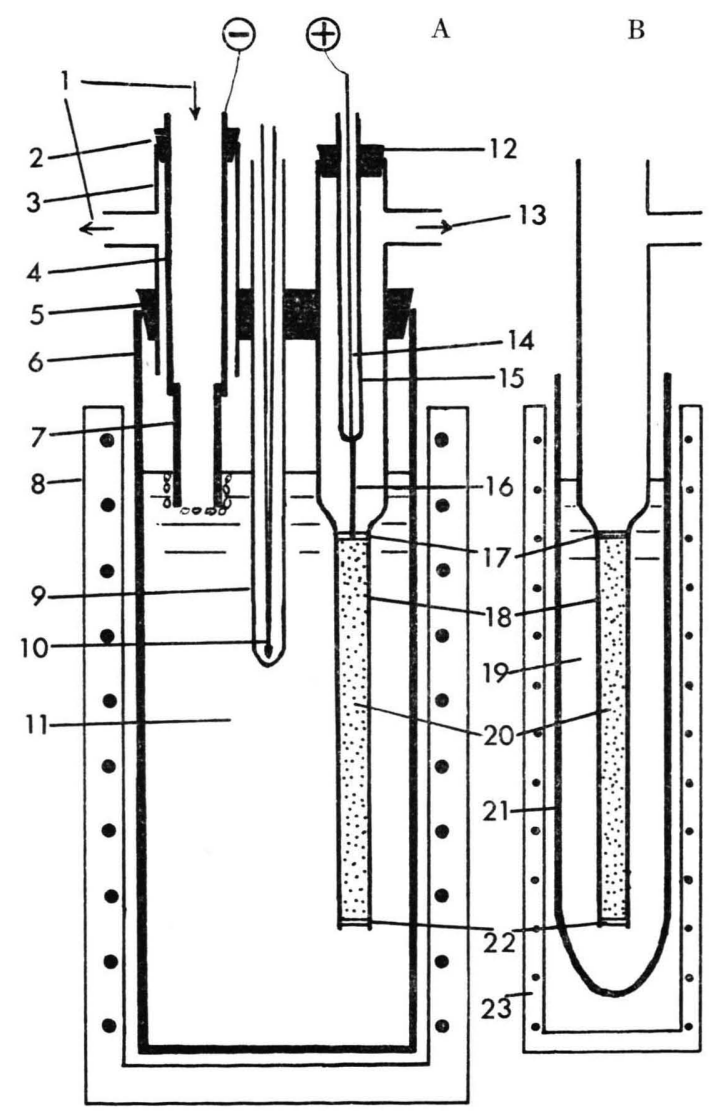

Fig. 1. Electromigration cell for molten $\mathrm{NaNO}_{3}$. A) Electromigration cell. B) Vessel for filling molten radioactive $\mathrm{NaNO}_{3}$ into the separation tube.

1, 13. Mixture of $\mathrm{NO}_{2}$ and $\mathrm{O}_{2} ; 2,5,12$. Silicone stopper; 3, 15. Pyrex glass tube; 4. Stainless steel tube; 6 . Quartz vessel (Int. diam.: $5.5 \mathrm{~cm}$, Hight : $30 \mathrm{~cm}$ ) ; 7 . Aluminum tube (Int. diam.: $9 \mathrm{~mm}$ ) ; 8, 23. Electric furnace; 9. Pyrex glass sheath for the thermocouple; 10. Thermocouple; 11. Molten $\mathrm{NaNO}_{3} ; 14$. Stainless steel wire; 16. Platinum wire (Diam.: $1 \mathrm{~mm}$ ) ; 17. Quartz wool (Thickness: ca. $5 \mathrm{~mm}$ ) ; 18. Separation tube $(\mathrm{Vy}$ cor glass); 19. Molten $\mathrm{NaNO}_{3}$ containing ${ }^{22} \mathrm{Na}$ and ${ }^{24} \mathrm{Na} ; 20$. Diaphragm (Quartz powder); 21. Pyrex glass vessel; 22. Quartz frit (Thickness: (Quartz powder); 21. Pyrex glass vessel;

The separation tube was placed so that the top of the diaphragm should be about $3 \mathrm{~cm}$ below the surface of the molten salt outside the tube, and the temperature was measured in the molten salt at ca. $10 \mathrm{~cm}$ depth. 
The decay of radioactivity in each section was followed with a well-type $\mathrm{NaI}(\mathrm{Tl})$ scintillation counter for more than $90 \mathrm{hr}$, that is, six times the half life of ${ }^{24} \mathrm{Na}$. At the time $t$, the radioactivity $A_{i}$ (counts per minute, $\mathrm{cpm}$ ) in the section $i$ is given by

$$
A_{i}=C_{i}{ }^{22} \exp \left\{-\lambda_{22} t\right\}+C_{i}{ }^{24} \exp \left\{-\lambda_{24} t\right\},
$$

where $\lambda_{22}$ and $\lambda_{24}$ are the decay constants of ${ }^{22} \mathrm{Na}$ and ${ }^{24} \mathrm{Na}$, respectively $\left(\lambda_{22}=5.11 \times 10^{-7} \mathrm{~min}^{-1}\right.$ and $\lambda_{24}=$ $7.70 \times 10^{-4} \mathrm{~min}^{-1}$ ), and $C_{i}{ }^{22}$ and $C_{i}{ }^{24}$ are the cpm of ${ }^{22} \mathrm{Na}$ and ${ }^{24} \mathrm{Na}$ at $t=0$, respectively. From Eq. (1), $C_{i}{ }^{22}$ and $C_{i}{ }^{24}$ for an arbitrary reference time were obtained with a least squares fit of $A_{i}(t)$.

After radioactivity counting, the salt in each section was dissolved in distilled water and filtrated from the quartz powder. An aliquot of the solution was thoroughly eluted through an anion exchanger of Cl-form, and the eluted chloride ion was titrated with a silver nitrate solution. Other aliquots were used for the determination of nitrate and oxide ion concentration.

\section{Results}

By plotting the count ratio $\left(a_{i}=C_{i}{ }^{24} / C_{i}{ }^{22}\right)$ in each section against the distance of the section from the anode, it was checked that the initial ratio remained unchanged in an extended part of the tube. Detailed electromigration results for one experiment are shown in Table 1.

In the previous investigation ${ }^{3}$, the quartz powder and the salt were packed one after the other a little at a time into the separation tube. However, with the present procedure, the separation tube could be packed more densely and uniformly, which made the effective diffusion coefficients (cf. Table 2) lower than in the previous experiment $\left[D_{\text {eff }}=\right.$ $(6-13) \cdot 10^{-5} \mathrm{~cm}^{2} / \mathrm{sec}$ at $340-380^{\circ} \mathrm{C}^{3}$ ]. A smaller effective diffusion coefficient makes the mass effect measurement more accurate.
The relative internal mobility difference between ${ }^{22} \mathrm{Na}$ and ${ }^{24} \mathrm{Na}$ was calculated according to the equation ${ }^{5}$

$$
\left(b_{22}-b_{24}\right) / b_{\mathrm{Na}}=\sum_{i}\left\{2\left(a_{i}-a_{0}\right) /\left(a_{i}+a_{0}\right)\right\} N_{i} F / Q
$$

where $a_{i}=C_{i}{ }^{24} / C_{i}{ }^{22}$ : the subscript 0 refers to a reference sample, $\mathrm{Ni}$ is the number of equivalents of $\mathrm{NaNO}_{3}$ in the section $i, Q$ the transported charge, and $F$ the Faraday constant. The summation was made from the section nearest to the anode to the section where no isotopic enrichment of ${ }^{24} \mathrm{Na}$ was detected.

The results are tabulated in Table 2 .

\section{Discussion}

The internal mass effect at $340^{\circ} \mathrm{C}$, i. e. approximately $5 \%$ (in ${ }^{\circ} \mathrm{K}$ ) above the melting point, is calculated to be $-0.056 \pm 0.002$ (weighted mean from experiments Nos. 1, 2 and 3). The error is the standard deviation of the mean. This value, measured for ${ }^{22} \mathrm{Na}$ and ${ }^{24} \mathrm{Na}$, agrees with the previously measured one for ${ }^{22} \mathrm{Na}$ and ${ }^{23} \mathrm{Na}^{3}$ within experimental error, although in the latter case the precision was low $\left[\mu_{\text {int }}=-0.045 \pm 0.006\right.$ (standard deviation) in the previous work].

This internal mass effect for $\mathrm{NaNO}_{3}$ fits quite well with the empirical rule

$$
-\mu_{\text {int }}=0.0848 /\left(1+m_{+} / 46\right),
$$

which LUNDÉN and EKHED ${ }^{6}$ have proposed for pure molten alkali nitrates at temperatures $5 \%$ above the melting points on the basis of the mass effect data of $\mathrm{LiNO}_{3}{ }^{6}, \mathrm{KNO}_{3}{ }^{7,8}$, and $\mathrm{RbNO}_{3}{ }^{8,9}$. Here $m_{+}$is

\begin{tabular}{|c|c|c|c|c|c|c|c|}
\hline $\begin{array}{l}\text { Section } \\
\text { No. }^{\mathrm{a}}\end{array}$ & $\begin{array}{l}\text { Length } \\
{[\mathrm{mm}]}\end{array}$ & $\begin{array}{l}22 \mathrm{Na} \\
{[\mathrm{cpm}]}\end{array}$ & $\begin{array}{l}{ }^{24} \mathrm{Na} \\
{[\mathrm{cpm}]}\end{array}$ & $\begin{array}{l}\text { Count ratio } \\
{ }^{24} \mathrm{Na} /{ }^{22} \mathrm{Na} \text { b }\end{array}$ & $\begin{array}{l}\text { Quantity of total } \\
\text { anion }^{\mathrm{c}}\left(10^{-4} \text { equiv. }\right)\end{array}$ & $\begin{array}{l}\text { Quantity of nitrite } \\
\left(10^{-5} \text { equiv. }\right)\end{array}$ & e $\%$ \\
\hline 1 & 14 & 1492 & 7295 & $4.89 \pm 0.03$ & $9.30 \pm 0.10$ & 0.6 & 1 \\
\hline 2 & 12 & 2150 & 8086 & $3.76 \pm 0.02$ & $10.95 \pm 0.03$ & 1.2 & 1 \\
\hline 3 & 13 & 2303 & 8256 & $3.59 \pm 0.01$ & $11.05 \pm 0.01$ & 0.4 & 0 \\
\hline 4 & 13 & 2494 & 8939 & $3.58 \pm 0.01$ & 14.95 & 4.9 & 3 \\
\hline 5 & 14 & 2793 & 9845 & $3.53 \pm 0.01$ & 13.75 & 4.9 & 3 \\
\hline 6 & 14 & 2734 & 9743 & $3.56 \pm 0.01$ & 12.40 & 5.3 & 4 \\
\hline 7 & 17 & 3213 & 10872 & $3.38 \pm 0.01$ & 16.95 & 4.4 & 3 \\
\hline 8 & 13 & 1886 & 5897 & $3.13 \pm 0.01$ & 15.15 & 4.9 & 3 \\
\hline 9 & 15 & 651 & 1704 & $2.62 \pm 0.02$ & 21.80 & 6.1 & 3 \\
\hline \multicolumn{4}{|c|}{ Un-electromigrated reference sample } & $3.59 \pm 0.01$ & & & \\
\hline
\end{tabular}
the mass of the cation. Another empirical relation

Table 1. Isotopic distribution after electromigration in $\mathrm{NaNO}_{3}$ (Expt. No. 3)

a Sections are numbered from the anode side.

b The errors correspond to the standard deviations of the mean for radioactivity counting.

c The errors are the mean deviations of several chemical analyses. Since the quantities in the sections from No. 4 to No. 9 were not needed for calculation of the mass effect, they were measured only once. 
Table 2. Data of experiments and results.

\begin{tabular}{|c|c|c|c|c|c|c|c|}
\hline Experiment No. & 1 & 2 & 3 & 4 & 5 & 6 & 7 \\
\hline Temperature $\left[{ }^{\circ} \mathrm{C}\right]^{\mathrm{a}}$ & $340 \pm 3$ & $340 \pm 3$ & $350 \pm 5$ & $430 \pm 10$ & $440 \pm 10$ & $510 \pm 10$ & $515+5$ \\
\hline Voltage $[\mathrm{V}]$ & 50 & $50-$ & 75 & $60-\overline{80}$ & $60-70$ & 40 & $40-\overline{50}$ \\
\hline Electric current $[\mathrm{mA}]$ & $90-100$ & $90-100$ & $70-90$ & $85-100$ & $90-100$ & $90-100$ & $90-100$ \\
\hline Duration $[\mathrm{hr}]^{\mathrm{b}}$ & 26 & 24 & 21 & 24 & 24 & 24.5 & 24 \\
\hline $\begin{array}{l}\text { Transported charge } \\
\text { [coulomb] }\end{array}$ & 7980 & 8390 & 6940 & 7850 & 9020 & 7370 & 8110 \\
\hline \multicolumn{8}{|c|}{ Separation tube (diaphragm) } \\
\hline Length $[\mathrm{mm}]$ & 121 & 132 & 126 & 143 & 137 & 114 & 136 \\
\hline Int. diam. [mm] & 4 & 4 & 4 & 4 & 4 & 4 & 4 \\
\hline $\begin{array}{l}\left.\text { Nitrite concn. }{ }^{\mathrm{c}}[\%] \mathrm{o}\right] \\
\text { Length of enrichment d }\end{array}$ & - & $2-3$ & $0-2$ & - & $4-6$ & $4-9$ & $2-7$ \\
\hline Jtop & 39 & 32 & 26 & 42 & 35 & 30 & 46 \\
\hline bottom $[\mathrm{mm}]$ & 30 & 38 & 45 & 76 & 57 & 50 & 58 \\
\hline $\int D_{\text {eff }} \quad\left(\mathrm{Na}\right.$ in $\left.\mathrm{NaNO}_{3}\right) \mathrm{e}$ & 5.2 & 3.8 & 2.9 & 6.5 & 4.5 & $3.3^{\mathrm{f}}$ & 7.8 \\
\hline$\left\{D_{\text {self }} \quad\left[\times 10^{-5} \mathrm{~cm}^{2} / \mathrm{sec}\right]\right.$ & 2.25 & 2.25 & 2.37 & 3.44 & 3.59 & 4.63 & 4,71 \\
\hline $\begin{array}{l}\text { Relative internal mobility } \\
\text { difference }^{\mathrm{g}}\left(b_{22}-b_{24}\right) / b_{\mathrm{Na}}\end{array}$ & $\begin{array}{l}0.0053 \\
\pm 0.0001\end{array}$ & $\begin{array}{l}0.0050 \\
\pm 0.0002\end{array}$ & $\begin{array}{l}0.0046 \\
\quad \pm 0.0001\end{array}$ & $\begin{array}{l}0.0067 \\
\quad \pm 0002.0\end{array}$ & $\begin{array}{l}0.0070 \\
\quad \pm 0.0003\end{array}$ & $\begin{array}{l}0.0045^{\mathrm{f}} \\
\pm 0.0001\end{array}$ & $\begin{array}{l}0.0060 \\
\pm 0.0001\end{array}$ \\
\hline $\begin{array}{l}\text { Internal mass effect } \mathrm{g} \\
-\mu_{\text {int }}\end{array}$ & $\begin{array}{l}0.061 \\
\pm 0.002\end{array}$ & $\begin{array}{l}0.058 \\
\pm 0.002\end{array}$ & $\begin{array}{l}0.053 \\
\pm 0.001\end{array}$ & $\begin{array}{l}0.077 \\
\pm 0.002\end{array}$ & $\begin{array}{l}0.081 \\
\pm 0.003\end{array}$ & $\begin{array}{l}0 . \overline{0} 52^{\mathrm{f}} \\
\pm 0.001\end{array}$ & $\begin{array}{l}0.068 \\
\pm 0.001\end{array}$ \\
\hline
\end{tabular}

a The temperature was measured in the molten salt in which the separation tube was immersed. The temperature difference between the inside and the outside of the tube was estimated to be about $1^{\circ} \mathrm{C}$, according to the equation presented by Herzog and KLemm*.

b In Exp. Nos. 3 and 6, electromigration was interrupted for about 2 hours.

c The nitrate content was measured for the sections near the anode where ${ }^{24} \mathrm{Na}$ was enriched, and the highest and the lowest values in these sections are given here. The oxide content was less than 1 mole \%.

d Enrichment of ${ }^{24} \mathrm{Na}$ and ${ }^{22} \mathrm{Na}$ was detected at the regions in the top and the bottom part of the separation tube, respectively.

e The effective diffusion coefficients were evaluated according to the relation $D_{\text {eff }}=l^{2} / \pi t * *$, where $l$ is the length of the region in which ${ }^{24} \mathrm{Na}$ was enriched, and $t$ is the duration of electromigration. The self-diffusion coefficients, which were estimated according to Ref. $*^{* *}$, are given here for a comparison.

f Since in Exp. No. 6, $D_{\text {eff }}$ is calculated to be lower than $D_{\text {self }}$, which is impossible theoretically, a little amount of enriched ${ }^{24} \mathrm{Na}$ seems to have streamed or leaked out. Therefore, the values of $\Delta b / b$ and $\mu_{\text {int }}$ in Exp. No. 6 are likely to be only a lower limit.

$\mathrm{g}$ The errors given are the standard deviaitons of the mean resulting from the errors in radioactivity counting and chemical analysis, which are calculated according to the equation presented in Ref. ${ }^{2}$.

* W. Herzog and A. Klemm, Z. Naturforsch. 13 a, 7 [1958]. *** J. C. Th. Kwak and J. A. A. Ketelaar, J. Phys. Chem.

** A. Klemm, Z. Phys. 123, 10 [1944]. 73, 94 [1969].

between the mass effect and the cationic radius $r_{+}$ proposed by them ${ }^{6}$ is

$$
-\mu_{\text {int }}=0.0523 / r_{+} \cdot
$$

According to Eqs. (3) and (4), the mass effect for $\mathrm{NaNO}_{3}$ is calculated to be -0.057 and -0.054 , respectively, where $r_{+}=0.97 \AA$ is adopted.

From the present internal mass effect, the external mass effect is evaluated to be $-0.079 \pm$ 0.002 at $340{ }^{\circ} \mathrm{C}$ according to the relation $\mu_{\text {ext }}$ $=\mu_{\text {int }} / t_{+}{ }^{10}$, where $t_{+}$is the external ransport number of sodium ion in $\mathrm{NaNO}_{3} \quad\left(t_{+}=0.71 \pm 0.01\right.$ l. c. $\left.{ }^{11,12}\right)$. This value agrees well with that measured with zone electromigration $\left(\mu_{\mathrm{ext}}=-0.081\right.$ at $360{ }^{\circ} \mathrm{C}$ for pure $\left.\mathrm{NaNO}_{3}{ }^{4}\right)$. Sodium nitrate is the only case, for which the isotope effect in zone electromigration of pure molten salts has been measured. Therefore, it is interesting to note that this agreement supports the expectation ${ }^{10}$ that the mass effects from both kinds of electromigration should agree with each other.

The mass effect has been measured at three different temperatures and was found to be higher at $435^{\circ} \mathrm{C}$ than at either lower $\left(340^{\circ} \mathrm{C}\right)$ or higher $\left(515{ }^{\circ} \mathrm{C}\right)$ temperature. Although it cannot be clearly concluded from the present data where the maximum of the mass effect occurs, it is deduced that a maximum point exists around $440^{\circ} \mathrm{C}$. If one assumes that the mass effect increases monotonically in the range $340-440{ }^{\circ} \mathrm{C}$, the temperature dependence is roughly expressed in that range by

$$
\begin{aligned}
-\mu_{\mathrm{int}}= & (0.0495 \pm 0.0024) \\
& +(0.000229 \pm 0.000037)\left(t^{\prime}-310\right),
\end{aligned}
$$

where $t^{\prime}$ is the temperature in ${ }^{\circ} \mathrm{C}$.

A maximum for the mass effect of sodium has also been found with zone electromigration ${ }^{4}$ in a mixture of 45 mole $\% \mathrm{NaNO}_{3}$ and 55 mole $\% \mathrm{KNO}_{3}$, 
studied over the range $253-435^{\circ} \mathrm{C}$. The highest values were found at about $370{ }^{\circ} \mathrm{C}$. In order to interpret the maximum of the external mass effect, Chemla and coworkers ${ }^{4}$ have assumed the existence of the species $\mathrm{Na}^{+}$and $\mathrm{NaNO}_{3}{ }^{0}$. Extending this model, we assume the existence of species such as $\mathrm{Na}^{+}, \mathrm{NaNO}_{3}{ }^{0}, \mathrm{Na}_{2} \mathrm{NO}_{3}{ }^{+}$and $\mathrm{Na}\left(\mathrm{NO}_{3}\right)_{2}{ }^{-}$. Various studies have shown that there are strong ionic interactions in molten nitrates. For example, Raman spectra of molten alkali nitrates have been interpreted in terms of localized ion-pair formation ${ }^{13}$, while on the other hand infrared results have been explained in terms of the existence of a quasi-crystalline structure ${ }^{14,15}$.

In general, the ratio of the net external electromigration velocities of two isotopes is given by

$$
\alpha=\sum_{i} u_{i} x_{i} / \sum_{i} u_{i}^{\prime} x_{i}^{\prime},
$$

where $x_{i}$ and $x_{i}^{\prime}$ are the proportions of the species $i$ containing light and heavy isotopes, respectively, and $\sum_{i} x_{i}=1, \sum_{i} x_{i}^{\prime}=1$. The $u$ 's are the external velocities of the species indicated by the super- and subscripts, respectively.

Now, let us define $k_{i}$ as the equilibrium constant of the isotopic exchange reaction $1^{\prime}+i \gtrless 1+i^{\prime}$ (the symbols here represent the species).

$$
k_{i}=x_{1} x_{i}^{\prime} / x_{1}{ }^{\prime} x_{i} \text {. }
$$

From Eqs. (6) and (7), it follows that

$$
\alpha=\frac{\sum_{i} u_{i} x_{i}}{\sum_{i} h_{i}^{-1} k_{i} u_{i} x_{i}}\left\{1+\sum_{i} x_{i}\left(k_{i}-1\right)\right\},
$$

where $h_{i}$ is defined as $h_{i}=u_{i} / u_{i}^{\prime}$.

If $\bar{u}=\sum_{i} u_{i} x_{i}$ is introduced, it follows from Eq. (8) by giving the linear approximation of the expansion in powers of the small quantities $\left(h_{i}-1\right)$, $\left(k_{i}-1\right)^{16}$

$$
\begin{aligned}
\alpha-1[ & \left.=(\Delta m / m)\left(\mu_{\mathrm{int}} / \boldsymbol{t}_{+}\right)\right] \\
& =\sum_{i} x_{i}\left\{\left(u_{i} / \bar{u}\right)\left(h_{i}-1\right)+\left(1-u_{i} / \bar{u}\right)\left(k_{i}-1\right)\right\} .
\end{aligned}
$$

Now, if one specifies $1={ }^{22} \mathrm{Na}, 2={ }^{22} \mathrm{Na}^{23} \mathrm{NaNO}_{3}$, $3={ }^{22} \mathrm{NaNO}_{3}, 4={ }^{22} \mathrm{Na}\left(\mathrm{NO}_{3}\right)_{2}$, and $i^{\prime}=$ the corresponding species of ${ }^{24} \mathrm{Na}$, and supposes $u_{3}=u_{3}{ }^{\prime}$ $=0$, one gets

$$
\begin{aligned}
\alpha-1= & x_{1}\left\{\frac{u_{1}}{\bar{u}}\left(h_{1}-1\right)\right\} \\
& +x_{2}\left\{\frac{u_{2}}{\bar{u}}\left(h_{2}-1\right)+\left(1-\left(\frac{u_{2}}{\bar{u}}\right)\right)\left(k_{2}-1\right)\right\} \\
& +x_{3}\left(k_{3}-1\right) \\
& +x_{4}\left\{\frac{u_{4}}{\bar{u}}\left(h_{4}-1\right)+\left(1-\left(\frac{u_{4}}{\bar{u}}\right)\right)\left(k_{4}-1\right)\right\} .
\end{aligned}
$$

Even if one assumes that $\left|k_{2}-1\right|,\left|k_{3}-1\right|$, and $\left|k_{4}-1\right|$ have such a high value as 0.03 at $440{ }^{\circ} \mathrm{C}$ due to quantum effects, $(\alpha-1)$ will decrease by $3 \%$ at most, as seen from Eq. (10), with the vanishing of $\left|k_{i}-1\right|$ at higher temperatures, while $\mu_{\text {int }}$ actually decreases by about $15 \%$ in the range 440 to $515{ }^{\circ} \mathrm{C}$. Thus, the decrease of $\mu_{\text {int }}$ in this temperature range cannot be attributed mainly to the decrease of the quantum effect.

If, for simplicity, the terms $\left(k_{i}-1\right)$ are neglected in Eq. (10), one obtains

$$
\alpha-1=\sum_{i}^{4} x_{i}\left(u_{i} / u_{1}\right)\left(h_{i}-1\right) / \sum_{i}^{4} x_{i}\left(u_{i} / u_{1}\right),
$$

where $u_{3}=0$ and $u_{4}<0$. The changes of $a-1$ as a function of temperature may be caused predominantly by the changes of $x_{i}$, and it is seen from Eq. (11) that, even if the terms $\left(u_{i} / u_{1}\right)$ and $\left(h_{i}-1\right)$ are supposed to be independent of temperature, the equation provides the possibility of a complicated temperature dependence including a maximum.

In the model in which only $\mathrm{Na}^{+}$and $\mathrm{NaNO}_{3}{ }^{0}$ are assumed ${ }^{4}$, the equation corresponding to Eq. (10) is given by

$$
\alpha-1=h_{1}-1+x_{3}\left(k_{3}-1\right), \quad x_{1}+x_{3}=1 .
$$

Chemla and coworkers ${ }^{4}$ have proposed that $x_{3}$ increases and $\left(k_{3}-1\right)$ decreases with rising temperature, thus produing a maximum of $\alpha$. However, their assumption that at low temperatures $x_{3}$ increases with rising temperature is difficult to accept, and, as mentioned above, at higher temperatures the decrease of the quantum effect $\left(k_{3}-1\right)$ cannot explain the large decrease of $\alpha$.

As far as the internal mass effect is concerned, the possibility of a decrease of the cationic external transport number with rising temperature must be taken into consideration. Actually, for $\mathrm{NaNO}_{3}$, there is an indication that the cationic transport number might decrease with increasing temperature. The transport number of $\mathrm{Na}$ in $\mathrm{NaNO}_{3}$ is evaluated from the mobility data ${ }^{12}$ to be 0.71 \pm 0.02 at $350{ }^{\circ} \mathrm{C}$ and $0.66 \pm 0.04$ at $450{ }^{\circ} \mathrm{C}$, although there are no data available above $450^{\circ} \mathrm{C}$. 
With regard to the nitrite content in the present experiments, it was $1-9$ mole $\%$ and almost the same as that in the case of $\mathrm{KNO}_{3}{ }^{7}$, where it has been found that the nitrite ion does not appreciably affect the mass effect for $\mathrm{KNO}_{3}$. Thus, it is supposed that in the present case the increase of nitrite concentration at higher temperature should not affect the mass effect appreciably.

An alternative explanation of the temperature dependence of $\mu_{\text {int }}$ in $\mathrm{NaNO}_{3}$ is possible. According to the model presented by JORDAN and KLEMM ${ }^{17}$, $\partial \ln \mu_{\text {int }} / \partial \ln T$ is related to $\partial \ln \left(D_{+} / T A\right) / \partial \ln T$, where $D_{+}$is the self-diffusion coefficient of the cation, $A$ the equivalent electric conductivity, and $T$ the absolute temperature, and both entities should have the same sign.

If we assume that the temperature dependence of both $D_{+}$and $\Lambda$ can be expressed by Arrhenius' equations, we find that

$$
\partial \ln \left(D_{+} / T \Lambda\right) / \partial \ln T=\left(\Delta H_{\mathrm{D}}-\Delta H_{\Lambda}\right) / R T-1 .
$$

For those salts for which the activation energy of self-diffusion, $\Delta H_{\mathrm{D}}$, is larger than that for electric conductivity, $\Lambda H_{A}$, we can expect that the temperature coefficient [Eq. (13)] is positive at low temperatures and negative at high. An estimation from Eq. (13) of the temperature at which the mass effect has its maximum must be very rough, and the result is strongly influenced by the choice of data on $\Delta H_{\mathrm{D}}$ and $\Delta H_{\Lambda}$.

For $\mathrm{NaNO}_{3}, \partial \ln \mu_{\text {int }} / \partial \ln T$ is evaluated from the present experiments to be $2.51 \pm 0.43$ at $340^{\circ} \mathrm{C}$. The value of $\partial \ln \left(D_{+} / T \Lambda\right) / \partial \ln T$, that is, $\left(\Delta H_{\mathrm{D}}-\Delta H_{\Lambda}\right) / R T-1$ and the temperature at which this entity changes from positive to negative are given in Table 3 according to the several sources of data on $\Delta H_{\mathrm{D}}$, where $\Delta H_{A}=3110 \pm 10 \mathrm{cal} / \mathrm{mole}$ $\left(325-425^{\circ} \mathrm{C}\right){ }^{18}$ is adopted. As is seen from Table 3 , the sign of $\partial \ln \left(D_{+} / T \Lambda\right) / \partial \ln T$ changes from positive to negative at $663 \pm 50{ }^{\circ} \mathrm{C}$, if $\Delta H_{\mathrm{D}}$ $=4970 \pm 80 \mathrm{cal} / \mathrm{mole}^{19}$ is selected. This presumes that the mass effect as a function of temperature would have a maximum value at $663 \pm 50{ }^{\circ} \mathrm{C}$, while the mass effect has actually the maximum around $440{ }^{\circ} \mathrm{C}$.

Thus, although the accuracy of the measured values for $\Delta H_{\mathrm{D}}$ and $\Delta H_{A}$ is not high enough to prove that $\partial \ln \mu_{\text {int }} / \partial \ln T$ is correlated with $\partial \ln \left(D_{+} / T A\right) / \partial \ln T$ in the case of $\mathrm{NaNO}_{3}$, this model seems to interpret qualitatively the temperature dependence of the internal mass effect for $\mathrm{NaNO}_{3}$.

It is interesting to note that for $\mathrm{NaNO}_{3}$ and $\mathrm{RbNO}_{3}{ }^{20}$ the mass effect has a maximum point as a function of temperature, while for $\mathrm{KNO}_{3}$ the mass effect increases with rising temperature over the whole studied range ${ }^{7}$, and for $\mathrm{LiNO}_{3}$ the influence of temperature is small ${ }^{21}$. Thus, the temperature dependence of the mass effect for alkali nitrates is complicated.

One of us (I. O.) would like to thank Professor A. LUNDÉN for helpful suggestions and a critical reading of the manuscript.

Table 3. Calculation based on the assumed correlation between electromigration mass effect, self-diffusion and conductivity. for $T=340^{\circ} \mathrm{C}$ and $\Delta H_{A}=3110 \pm 10 \mathrm{cal} / \mathrm{mole}{ }^{18}$.

\begin{tabular}{lllll}
\hline $\begin{array}{l}\text { Selected } \Delta H_{\mathrm{D}} \\
{[\mathrm{cal} / \mathrm{mole}]}\end{array}$ & & $\left(\Delta H_{\mathrm{D}}-\Delta H_{\Lambda}\right) / R T-1$ & $\begin{array}{l}\text { Sign change at } \\
{\left[{ }^{\circ} \mathrm{C}\right]}\end{array}$ & Ref. for $\Delta H_{\mathrm{D}}$ \\
\hline $4060 \pm 240$ & $\left(320-450^{\circ} \mathrm{C}\right)$ & $-0.22 \pm 0.21$ & $180 \pm 130$ & Tab. $2^{* * *}$ \\
$4300 \pm 300$ & $\left(350-420^{\circ} \mathrm{C}\right)$ & $-0.02 \pm 0.25$ & $330 \pm 160$ & $*$ \\
$4970 \pm 80$ & $\left(310-380^{\circ} \mathrm{C}\right)$ & $0.53 \pm 0.07$ & $663 \pm 50$ & 19 \\
$5000 \pm 700$ & $\left(320-400^{\circ} \mathrm{C}\right)$ & $0.55 \pm 0.53$ & $680 \pm 360$ & $* *$ \\
$5300 \pm 400$ & $\left(325-358^{\circ} \mathrm{C}\right)$ & $0.79 \pm 0.34$ & $830 \pm 210$ & $* * *$ \\
\hline
\end{tabular}

* M. K. Nagarajan and J. O’M. Bockris, J. Phys. Chem. 70, 1854 [1966].

* F. Lantelme and M. Chemla, Bull. Soc. Chim. France 1963, 969. - F. Lantelme, Thesis, Paris 1965.

1 The data are summarized, e. g. in A. KLEMm and K. HeINZINGER, Adv. Chem. Series 89, 246 [1969] and Ref. ${ }^{6}$.

2 I. OKada and N. SAito, Bull. Chem. Soc. Japan 43, 394 [1970].
S. Forcheri and V. Wagner, Z. Naturforsch. 22 a, 117] [1967].

3 N. Saito, I. Tomita, and I. Okada, J. Nucl. Sci. Technol. 3,140 [1966].

4 S. Wuhl, F. Lantelme, and M. Chemla, J. Chim. Phys. 65, 488 [1968]. 
5 Cf. A. Klemm, Z. Naturforsch. 1, 252 [1946].

6 A. Lundén and A. EKHEd, Z. Naturforsch. 24 a, 892 [1969].

7 A. Lundén and A. Ekhed, Z. Naturforsch. 23 a, 1779 [1968].

8 I. OKADA, Thesis, Tokyo University 1966.

9 A. LundÉn, Z. Naturforsch. 21 a, 1510 [1966].

10 A. LundÉN, Z. Naturforsch. 14 a, 801 [1959].

11 F. R. Duke and B. Owens, J. Electrochem. Soc. 105, 548 [1958].

12 E. P. Honig and J. A. A. Ketelaar, Trans. Faraday Soc. 62, 190 [1966].

13 S. C.WAit and A.T.WARD, J. Chem. Phys. 44, 448 [1966]; S. C. WAIT, A. T. WARD, and G. J. JANZ, J. Chem. 45, 133 [1966].

14 K. Williamson, P. Li, and J. P. Devlin, J. Chem. Phys. 48, 3891 [1968].

15 G. H. Wegdam, R. Bonn, and J. van der Elsken, Chem. Phys. Letters 2, 182 [1968].
16 Equation (9) is derived either from Equation (8) or easily from the equation presented by A. KLEMM, Z. Naturforsch. 3 a, 127 [1948].

17 S. Jordan and A. Klemm, Z. Naturforsch. 21 a, 1584 [1966].

18 The activation energy is evaluated from the data of B. DE NOolJer, Thesis, University of Amsterdam 1965.

19 A. S. Dworkin, R. B. Escue, and E. R. van Artsdalen, J. Phys. Chem. 64, 872 [1960].

20 A. Lundén, A. Floberg, and R. Matsson, to be published.

21 For $\mathrm{LiNO}_{3}$, the temperature dependence of $\mu_{\text {int }}$ has been measured in two laboratories, see Refs. ${ }^{6}$ and ${ }^{8}$, the result being that the mass effect either is independent of the temperature ${ }^{6}$, or that it decreases slightly when the temperature increases ${ }^{8}$. Possible causes of the discrepancy are discussed in Ref. ${ }^{6}$.

\title{
Dissociation Lifetimes of Molecular Ions Produced by Charge Exchange*
}

\author{
B. ANDLAUER ** and Ch. OTtINGER *** \\ Physikalisches Institut der Universität Freiburg, Germany \\ (Z. Naturforsch. 27 a, 293-309 [1972] ; received 27 November 1971)
}

\begin{abstract}
Ions of the benzonitrile, benzene and thiophene molecules were produced in well-defined states of excitation by charge exchange with $\mathrm{Xe}^{+}, \mathrm{Kr}^{+}, \mathrm{Ar}^{+}, \mathrm{CO}^{+}$, and $\mathrm{N}_{2}^{+}$. Their subsequent unimolecular decomposition was followed, as a function of time, by allowing the dissociations to take place within a strong homogeneous draw-out field and measuring the kinetic energy of the product ions. The decompositions were found to be purely exponential within experimental error, and the corresponding decay rate constants $k$ (for $2 \cdot 10^{5} \mathrm{sec}^{-1} \leqq k \leqq 5 \cdot 10^{8} \mathrm{sec}^{-1}$ ) proved to be monotonically increasing functions of the excitation energy. These are the first unambiguous measurements of this function $k(E)$ for any molecule. In the case of benzene, the reactions $\mathrm{C}_{6} \mathrm{H}_{6}{ }^{+} \rightarrow \mathrm{C}_{6} \mathrm{H}_{5}{ }^{+}+\mathrm{H}$ and $\mathrm{C}_{6} \mathrm{H}_{6}{ }^{+} \rightarrow \mathrm{C}_{4} \mathrm{H}_{4}{ }^{+}+\mathrm{C}_{2} \mathrm{H}_{2}$ were found to be definitely not in competition with one another. Furthermore the dependence of the excitation energy on the impact energy was measured. A variation of

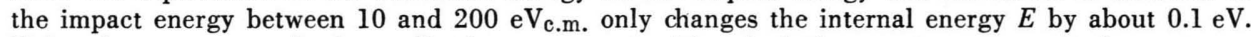
This value appears to be in qualitative agreement with calculations on near-resonant charge transfer by Gurnee and Magee.
\end{abstract}

\section{Introduction}

Unimolecular decompositions of excited polyatomic ions play an important role in many radiochemical and radiobiological systems as well as in organic mass spectrometry. An understanding of the host of possible concurrent and consecutive reactions has to be founded on a consistent picture of the time scale as well as the energetics of the unimolecular processes. Today still very little is known about the decomposition rate constant $k$ of isolated excited ions, and even less about the dependence of $k$ on the excitation energy $E$. In prin-

* This work is a summary of the Diplomarbeit of B. ANDLAUER, Universität Freiburg 1970.

* Present address: Institut für Angewandte Festkörperphysik, Freiburg. ciple the function $k(E)$ can be calculated within the framework of the quasi-equilibrium theory, henceforth abbreviated as QET ${ }^{1}$. However, the great number of assumptions necessary for any such calculation makes an experimental determination of $k(E)$ highly desirable. In previous communications ${ }^{2,3}$ we have reported on a method for measuring, in a well-defined manner, the decomposition rate of ions produced by electron impact. Subsequently we have been able, by means of varying the electron energy, to extract from these measurements $k(E)$ for a few decompositions of benzonitrile, butane and heptane ions ${ }^{4,5}$. However, this

\footnotetext{
*** Present address: Max-Planck-Institut für Strömungsfor-
} schung, Göttingen. 